\title{
Using Mask Technique and Center Detection for Congenital Dislocation of the Hip (CDH) Diagnosis
}

\author{
Nidal H. AL-Assady \\ College of Computer Sciences and Mathematics \\ Mafaz M. Khalil Alaniezi \\ mafazmhalanezi@uomosul.edu.iq \\ College of Sciences \\ University of Mosul, Iraq \\ Shahla H. Ahmad \\ Dentistry College
}

\section{Received on: 18/10/2006}

Accepted on: 05/03/2007

\section{ABSTRACT}

The aim of this study, is the diagnosis of Congenital Dislocation of the Hip (CDH) from routine X-Ray Image by measuring the retardation of the growth center of the head of femur bone in the abnormal joint in comparison with the normal side in cases of unilateral CDH using Mask Technique and algorithm of Center Detection and measurement. What is new about this study in comparison with the previous methods about diagnosis of $\mathrm{CDH}$ (which used artificial technique images matching subject to detect the diseased image only by compare the diseased images with normal image without giving any percent of disease) can be summarized by:

1.Going into the details of the X-Ray and cutting out the necessary parts ( head of femur ) for both the diseased and normal sides in cases of unilateral $\mathrm{CDH}$, to make comparison between them instead of using the complete image.

2.Using Mask Technique and algorithm of Center Detection to extract the features (Center, Intensity value of the center, and Diameter ) from the two captured images. Then we do a comparison for both sides for these features using Euclidean Distance to know the diseased side from the normal one.

We applied this system in computer using Matlab 7.0 programming Langue. Keywords: Congenital Dislocation of the Hip $(\mathrm{CDH})$, Mask Technique, Euclidean Distance.

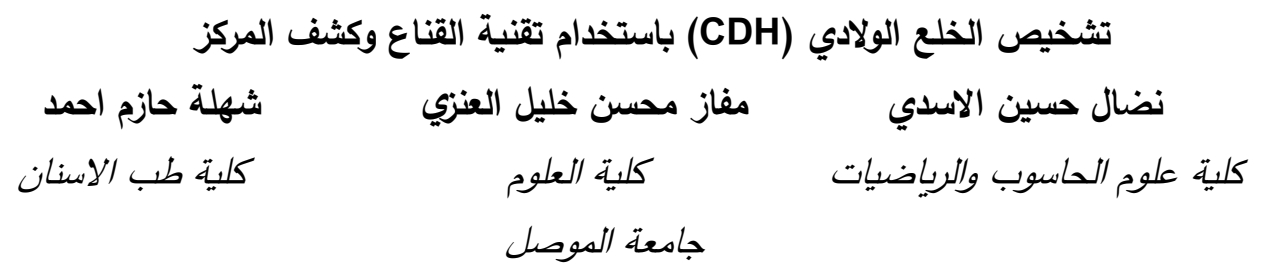


تاريخ قبول البحث: 2007/03/05 - (205

تاريخ استلام البحث: 2006/10/18

الملخص

الهدف من هذا البحث هو عملية تشخيص الخلع الولادي من خلال صور الأشعة السينية

ب-Ray

ويمكن تلخيص الجديد في هذا البحث بالمقارنة بالبحوث السابقة التي اهتمت بالخلع الولادي(التي

استخدمت التقنيات الذكائية ضمن موضوع تطابق الصور لتمييز المرض فقط بمقارنة الصور

المريضة بالطبيعية دون إعطاء أية نسبة للمرض) بما يأتي:

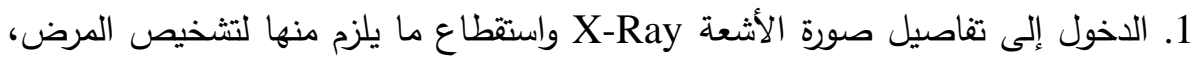

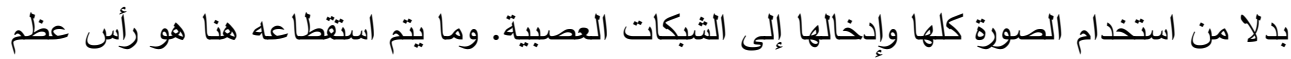

الفخذ head of femur لكلا الجهتين اليمنى و اليسرى من الحوض. أي ستكون لدينا جهة مريضة

وأخرى سليمة تتم مقارنة المريضة بها.

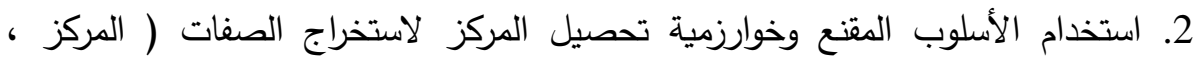

الكثافة اللونية للمركز ، والقطر) من الصورتين المستقعتين. وتتم مقارنة هذه الصفات لكلتا الجهتين

باستخدام المسافة الإقليدية لمعرفة الجهة المريضة من السليمة.

تم تطبيق هذا النظام حاسوبيا باستخدام اللغة البرمجية Matlab 7.0 .

الكلمات المفتاحية: الخلع الولادي (CDH) ، تقنية القناع ، المسافة الإقليدية.

\section{Introduction}

The upper end of the femur is formed of cartilage (which is invisible in X-ray) in the new born. As the child grows it gradually transforms into bone (which is visible on $\mathrm{x}$-ray or radio opaque). The upper end of the femur (also called head of femur) normally becomes radio opaque at 4-6 months of age (figure 1) [1]. This ossification center is typically seen earlier in females than in males, and there is a wide normal variation for the time of appearance. Although some asymmetry between the left and right hips both in time of appearance and size can be normal. However, several conditions can affect this growth end of the bone retarding both the time of its appearance and its size. The most common one of these conditions is congenital dislocation of the hip (CHD) which can be defined as a hip joint abnormality in which the head of femur (tends to be ) outside its socket at birth or soon after. Accurate measurement of the head of femur aids in early diagnoses and follow-up of $\mathrm{CDH}[2]$. 
The current study aims at establishing the basis for computerized auto detection and measurement of the head of femur and comparing its size with the normal side in cases of unilateral $\mathrm{CDH}$ utilizing the traditional $\mathrm{X}$ Ray films.

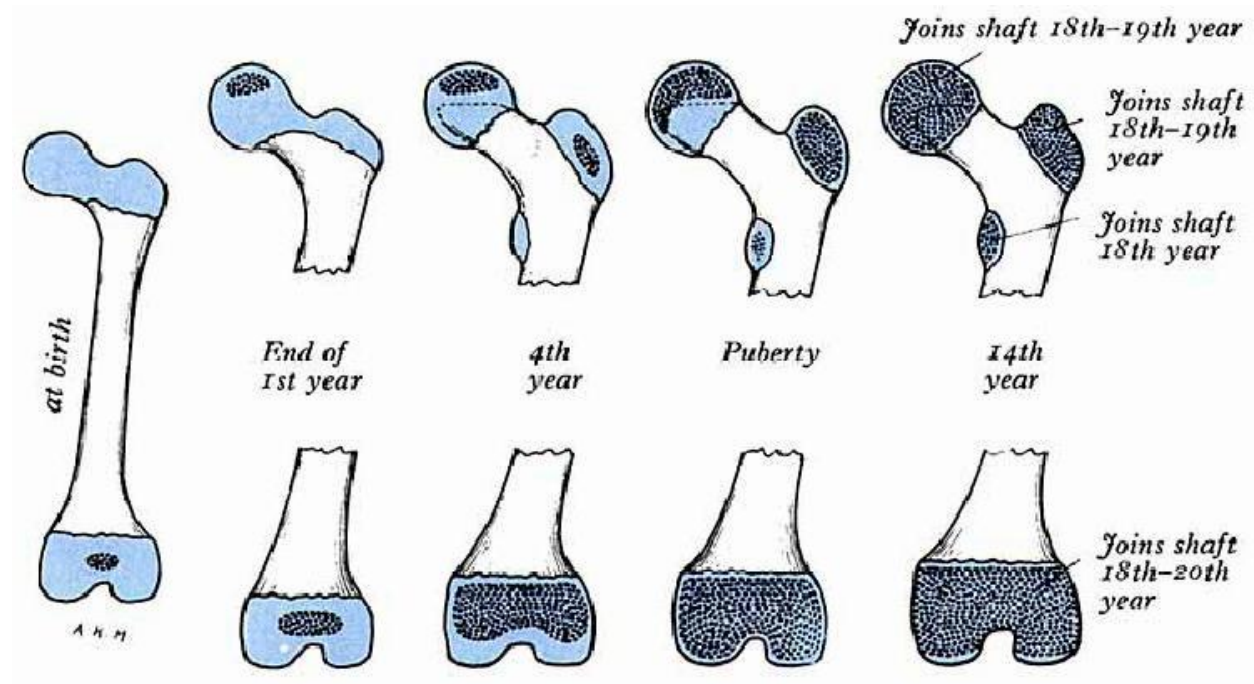

Figure (1): Growth of head of femur during human life.

\section{The Applied Segmentation Techniques}

Convolution is used in the applied head of femur segmentation as a basic technique for detection. The convolution process is an efficient process used in head of femur detection system.

Generally, the convolution process requires overlay the mask on the image, multiplying the coincidence values and summing all these results. The pixels of the output image must be stored in a separate image array called a buffer so that the existing values are not overwritten during the convolution process [3].

\section{Head of Femur Detection}

The X-Ray region taken for $\mathrm{CDH}$ is too large, so we capture the head of femur in a separate image. The head of femur is almost like a circle, therefore novel techniques are proposed using mask, profile and 
combination between them for detection of center of the head of femur. These techniques give high accuracy and reduce the execution time required to detect the head of femur.

Basically, the captured image has unadvisable space. This unadvisable space could be reduced by segmenting the head of femur image into $(8 \times 8$ pixel,64pixel (8bits per pixel)) segments, figure(2) (Note, we try another size of mask like $(32 \times 32$ pixel $)$ and $(16 \times 16$ pixel $)$ but we found mask $(8 \times 8$ pixel $)$ has the better result).

The used search space is the segment that has the maximum average of intensity value. This reduced search space is used in the next head of femur center detection steps.

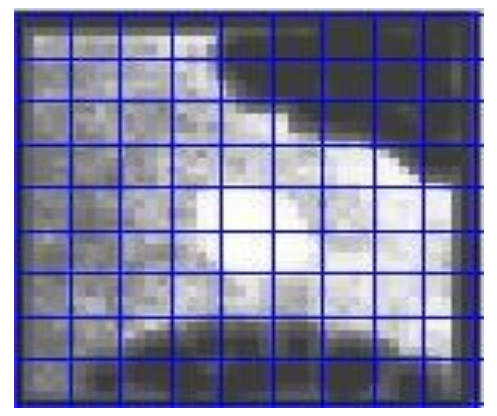

Figure (2): The reduced search space in a head of femur for the right side.

\section{Head of Femur Detection Using Mask}

After segmentation to reduce search space, the convolution process is applied using a mask $(2 \times 2)$ with ones coefficients (Note, we select mask $(2 \times 2)$ which is a small area because we search on the center pixel which is one pixel). The result of the average masked points in an image is stored in a vector and reduced by threshold. The indices of minimum and maximum values in the reduced vector are considered to be the starting and ending coordinates of the head of femur center. Then we search in this $(2 \times 2)$ matrix on the value that is repeated more, which is to be the centre of the head of femur.

\section{Diameter Detection by Profile}

The profile is a tool of an image processing technique. The profile of an image region is a projection of compact representation in the spatial pixel content distribution and has been successfully employed in this work. It is 
the set of intensity values taken from regularly spaced points along a line segment or multi-line path in an image. It could be applied for horizontal or vertical direction [5]. The horizontal projection profile of an image region is the projection profile for image obtained in row direction while the vertical projection profile is the projection of image obtained in column direction [6].

A novel application is proposed for the technique of diameter detection by profile. The head of femur center is calculated by finding the maximum occurrence of an intensity value in the rows and columns. The center lies on white region; therefore the highest intensity value has the maximum occurrence in the profile. The column index of the maximum occurrence represents the $X$ coordinate of the head of femur center. The row index of the maximum occurrence represents the $Y$ coordinated of head of femur center.

Figure (3) shows the center and the circle that we calculate diameter for it later, the circle is drawn on the real image (a), and on a contour plot of the intensity image values in gray scale (b).

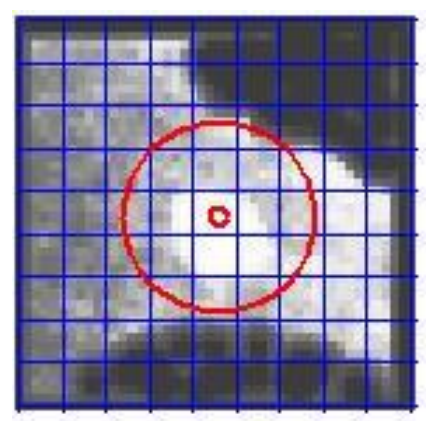

(a)

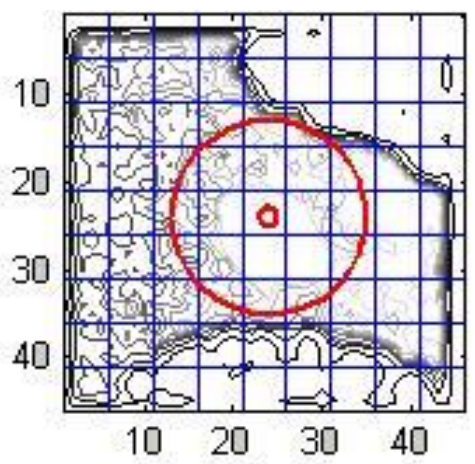

(b)

Figure (3): Center and diameter, (a) The real image. (b) Color map of image.

The profile of diameter for a column and a row across the center for the image in figure (3) above, is shown in Figure(4) . 


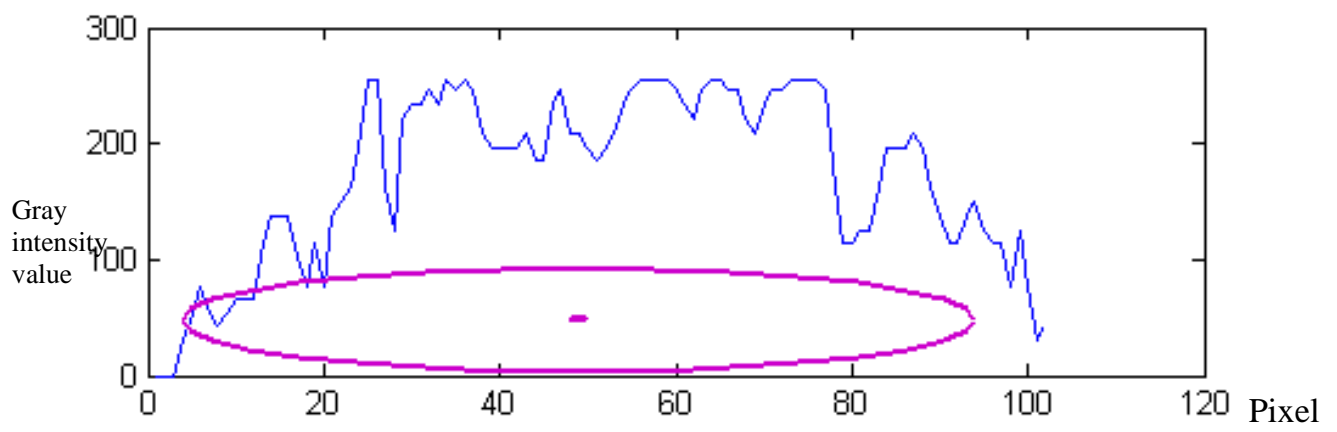

The $\mathrm{x}$ radius

(a)

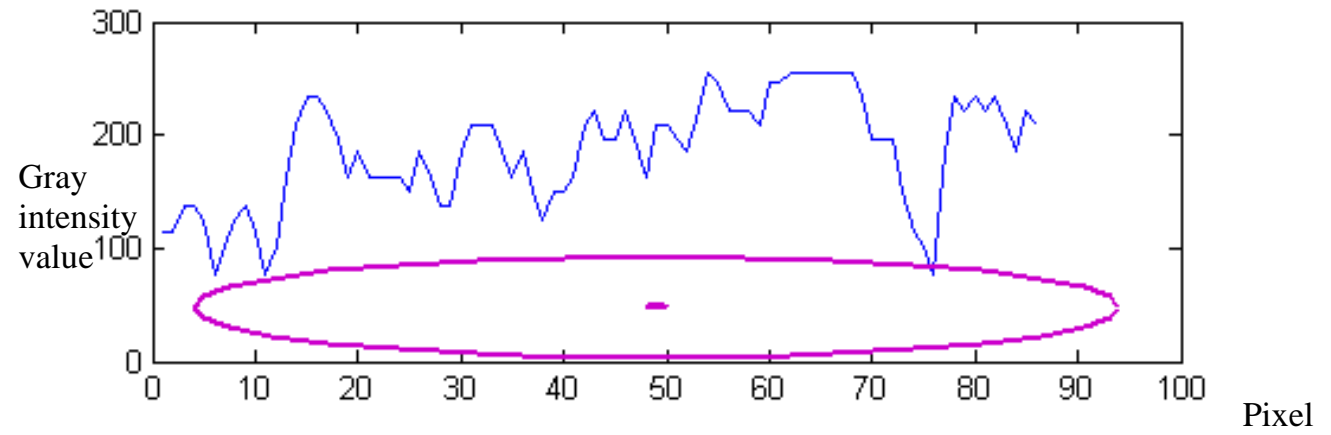

The $\mathrm{Y}$ radius

(b)

Figure (4): The Center and the radius of head of femur and the intensity value of pixels across radius $\mathrm{X}$ and $\mathrm{Y}$.

The radius of the head of femur RAD as shown in the figure (3) above, is calculated as the average of two calculated radii $\mathrm{R} 1$ and $\mathrm{R} 2$. The radius $\mathrm{R} 1$ is calculated from the minimum values of column profile compared with $\mathrm{X}$ coordinate of the center, denoted as COLmin. Then the radius $\mathrm{R} 1$ is calculated according to the following equation: 


\section{$R 1=\operatorname{abs}(X-C O L \min )$}

The radius $\mathrm{R} 2$ is calculated from the minimum values of row profile compared with $\mathrm{Y}$ coordinate of the center, denoted as $\mathrm{ROW}_{\min }$. Then the radius $\mathrm{R} 2$ is calculated according to the following equation:

\section{$\mathbf{R} 2=\operatorname{abs}\left(\mathbf{Y}-\mathbf{R O W}_{\min }\right)$}

Now, we have two radius values one for column R1 and another for row R2, The Diameter DIAM of the head of femur is calculated according to the following equation:

\section{DIAM $=\mathbf{R} 1+\mathbf{R} 2$}

While, The radius RAD of the head of femur is calculated according to the following equation:

$$
\mathrm{RAD}=(\mathrm{R} 1+\mathrm{R} 2) / 2
$$

Note, the diameter and the radius are in pixel, so we divide them on the resolution of images to obtain them in centimeter, but this size dose not represent the real size of head of femur because it depends on how we picture the image (perspective effect), so we compute the percentage of diameter size between diseased and normal sides which is the most important feature for diagnosis.

The flow chart for head of femur detection using mask and diameter detection by profile is shown in Figure (5).

\section{Euclidean Distance}

The Euclidean distance (ED) can be used to compare two templates, especially if template is composed of integer values. The Euclidean distance gives a measure of how similar a collection of values is between two templates [4]. The Euclidean distance D between two vectors $\mathrm{X}$ and $\mathrm{Y}$ is:

$$
\mathrm{ED}=\sum\left((\mathrm{X}-\mathrm{Y}) \cdot \wedge^{\wedge} 2\right) \cdot{ }^{\wedge} 0.5
$$

We apply the Euclidean distance on the features that we extracted earlier. The difference between the Euclidean distances elicited from the healthy and the diseased femoral heads for the same patient with unilateral $\mathrm{CDH}$ implies the retarding effect of this abnormality on the growth of this 
bone. Thus, the abnormal side is expected to be smaller and the greater this difference the more significant the results are.

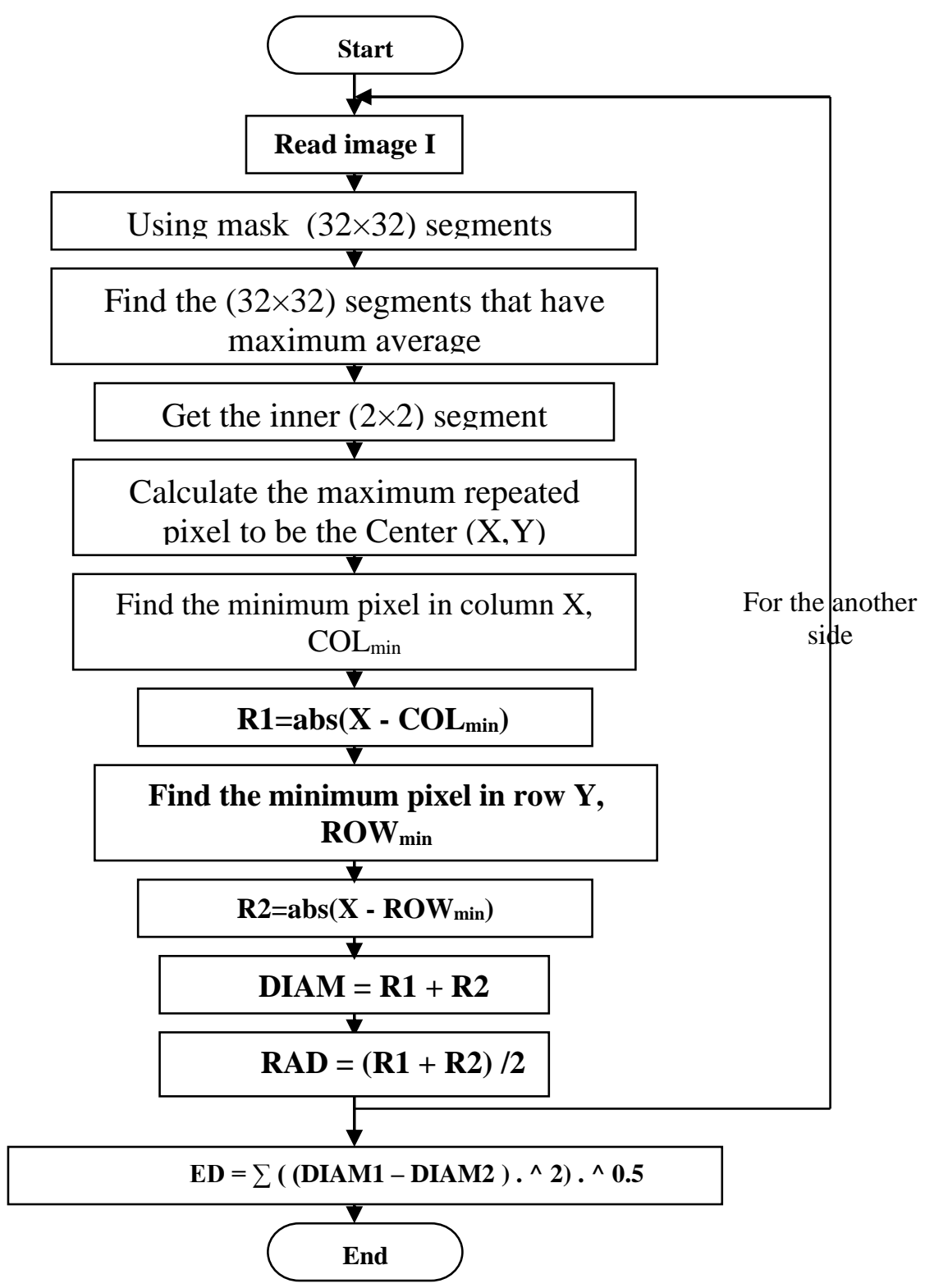

Figure (5): Flow chart of head of femur detection using mask and diameter detection by profile. 


\section{Results}

1. Image for right $\mathrm{CDH}$, show figure (6).

Diseased Right side result :
a. $\operatorname{Center}(X, Y)=(20,36)$
b. Diameter $=1.3582$
c. Center Intensity $=241$

Normal Left side result :
a. $\operatorname{Center}(\mathrm{X}, \mathrm{Y})=(24,32)$
b. Diameter $=1.8874$
c. Center Intensity $=255$

Euclidean result :

a. $\operatorname{Center}(\mathrm{X}, \mathrm{Y})=(4,4)$

b. Diameter $=0.5292 \&$ Percentage $=71.9626 \%$ of diseased side from normal side

c. Center Intensity $=14$ 


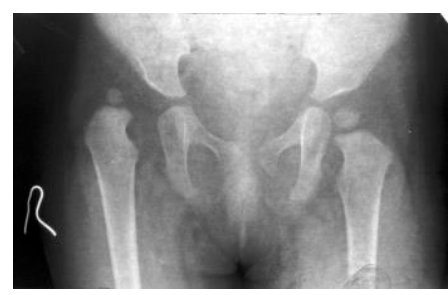

(a)

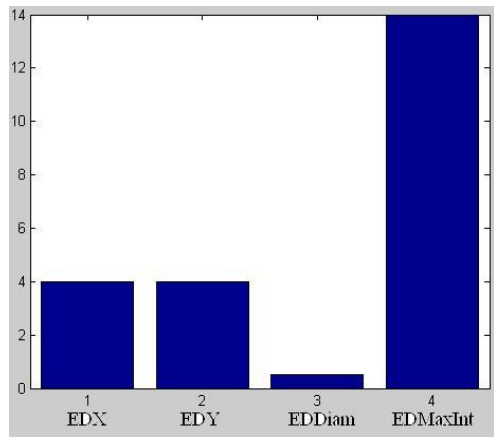

(c)

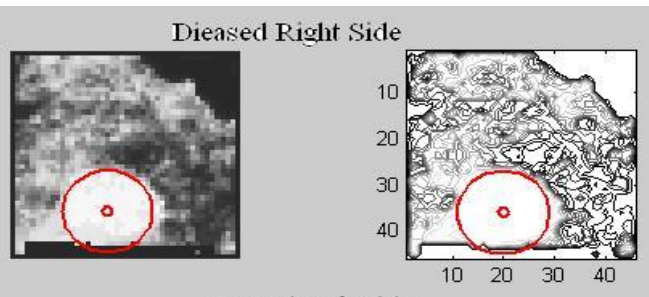

Nomal Left side
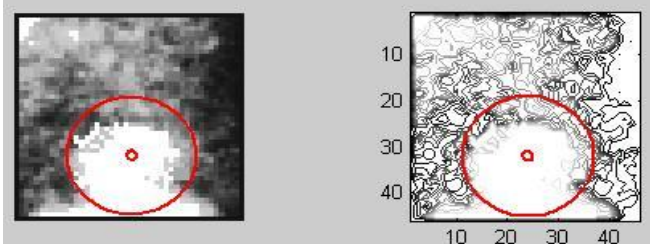

(b)

Figure (6): (a) Right CDH. (b) Result of Program. (c) Euclidean Result.

2. Image for left CDH, see figure (7).

Diseased Left side result :

a. $\operatorname{Center}(X, Y)=(20,40)$

b. Diameter $=1.2700$

c. Center Intensity $=197$

Normal Right side result :
a. $\operatorname{Center}(\mathrm{X}, \mathrm{Y})=(25,36)$
b. Diameter $=2.5753$
c. Center Intensity $=233$

Euclidean result :

a. $\operatorname{Center}(\mathrm{X}, \mathrm{Y})=(5,4)$ 
b. Diameter $=1.3053 \&$ Percentage $=49.3151 \%$ of diseased side from normal side

c. Center Intensity $=36$

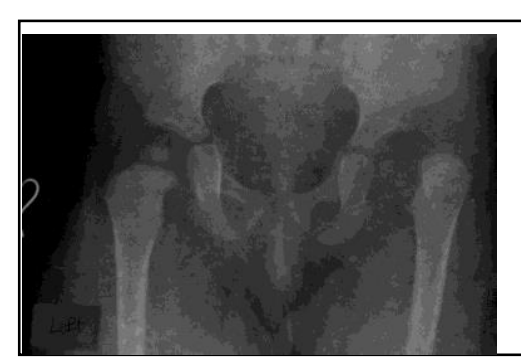

(a)

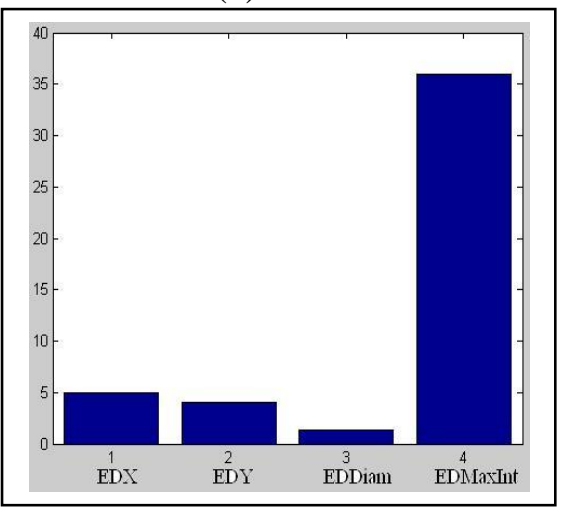

(c)

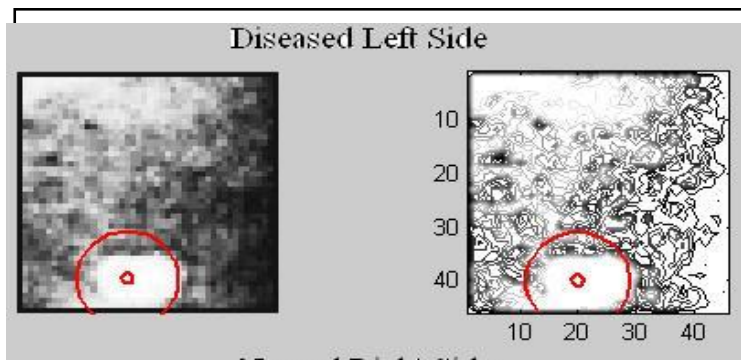

Normal Right Side

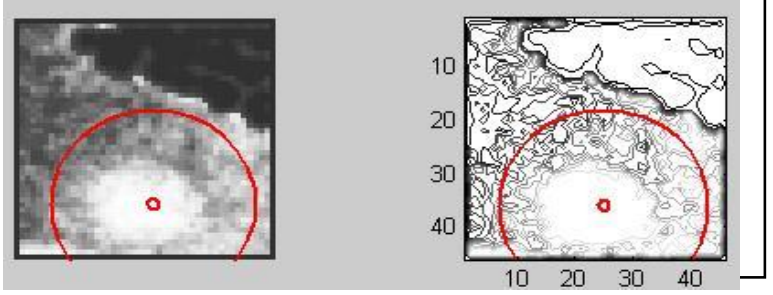

(b)

Figure (7): (a) Left CDH. (b) Result of Program. (c) Euclidean Result.

\section{Image for left CDH, see figure (8).}

Diseased Left side result :
a. $\operatorname{Center}(\mathrm{X}, \mathrm{Y})=(25,20)$
b. Diameter $=0.9702$
c. Center Intensity $=100$

Normal Right side result :
a. $\operatorname{Center}(\mathrm{X}, \mathrm{Y})=(24,28)$
b. Diameter $=1.7992$
c. Center Intensity $=191$

Euclidean result :

a. $\operatorname{Center}(\mathrm{X}, \mathrm{Y})=(1,8)$ 
b. Diameter $=0.8290 \&$ Percentage $=53.9216 \%$ of diseased side from normal side

c. Center Intensity $=91$

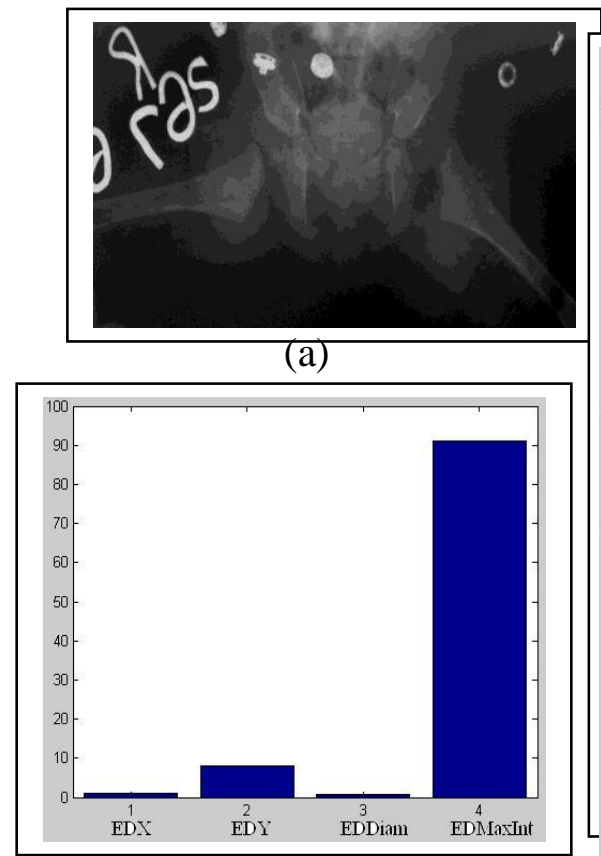

(c)

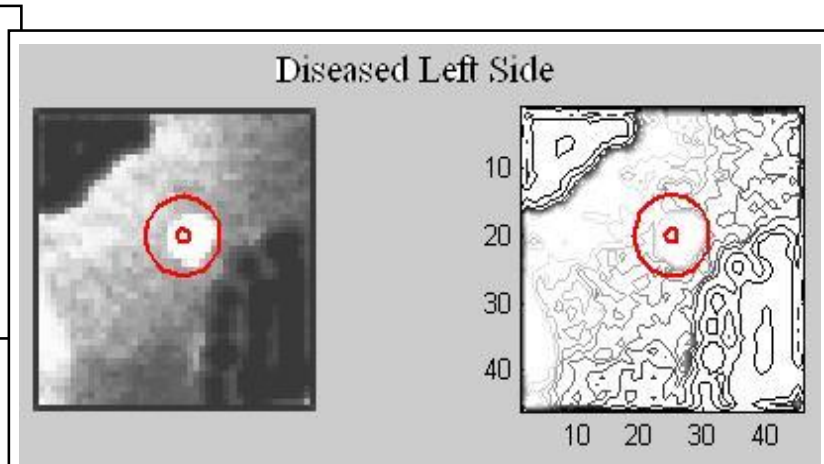

Nommal Right Side

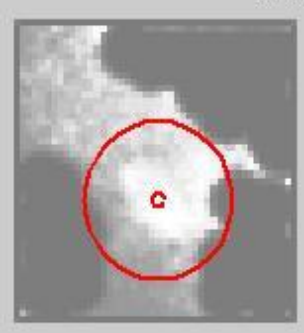

(b)

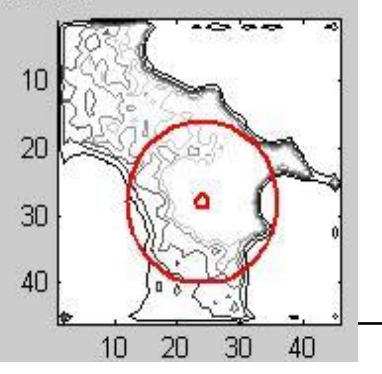

Figure (8): (a) Left CDH. (b) Result of Program. (c) Euclidean Result.

4. Image for left $\mathrm{CDH}$, see figure (9).

Diseased Left side result :

a. $\operatorname{Center}(\mathrm{X}, \mathrm{Y})=(20,28)$

b. Diameter $=1.1465$

c. Center Intensity $=172$

Normal Right side result :

a. $\operatorname{Center}(\mathrm{X}, \mathrm{Y})=(24,24)$

b. Diameter $=1.6228$

c. Center Intensity $=251$

Euclidean result :

a. $\operatorname{Center}(\mathrm{X}, \mathrm{Y})=(4,4)$ 
b. Diameter $\quad=0.4763 \&$ Percentage $=70.6522 \%$ of diseased side from normal side

c. Center Intensity $=79$

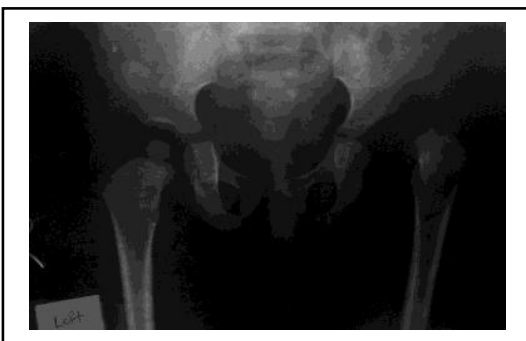

(a)

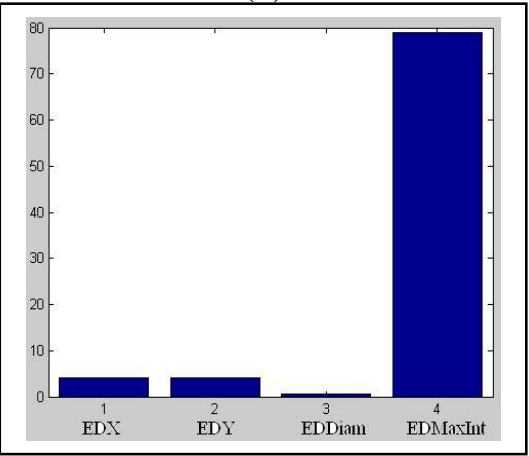

(c) Figure (9): (a) Left CDH. (b) Result

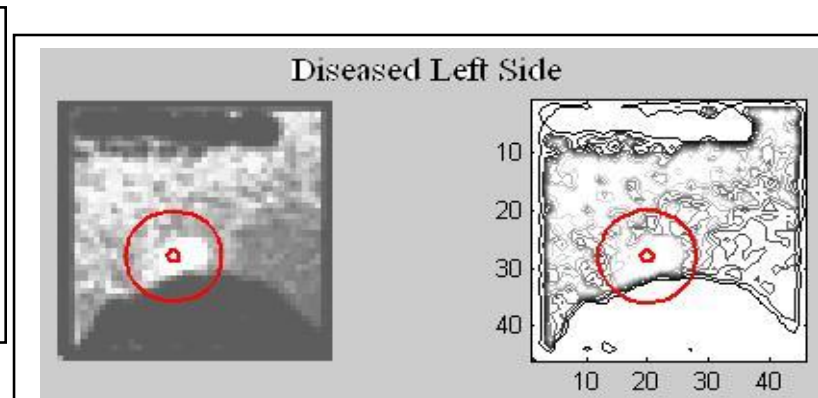

Normal Right Side
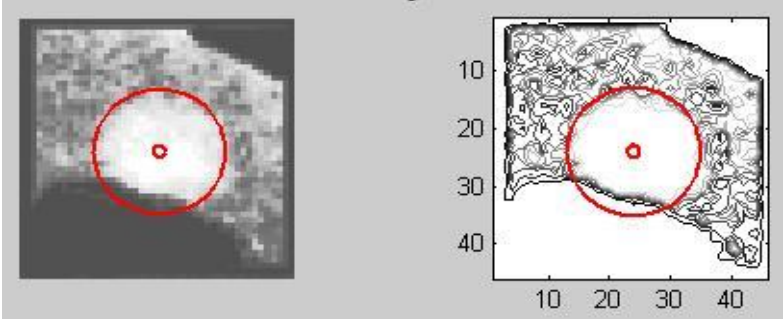

(b) of Program. (c) Euclidean Result.

\section{Image for Normal case, see figure (10).}

Right side result :
a. $\operatorname{Center}(\mathrm{X}, \mathrm{Y})=(24,24)$
b. Diameter $=1.6757$
c. Center Intensity $=234$

Left side result :
a. $\operatorname{Center}(\mathrm{X}, \mathrm{Y})=(16,32)$
b. Diameter $=1.5170$
c. Center Intensity $=242$

Euclidean result :

a. $\operatorname{Center}(\mathrm{X}, \mathrm{Y})=(8,8)$ 
b. Diameter $=0.1588 \&$ Percentage $=110.4651 \%$ of right side from left side.

c. Center Intensity $=8$

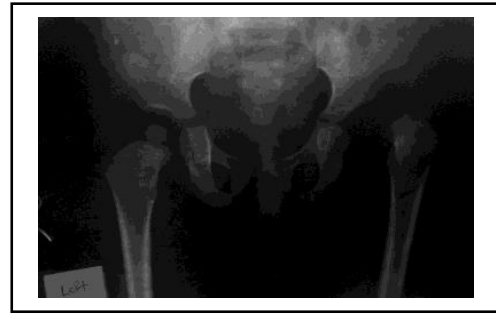

(a)

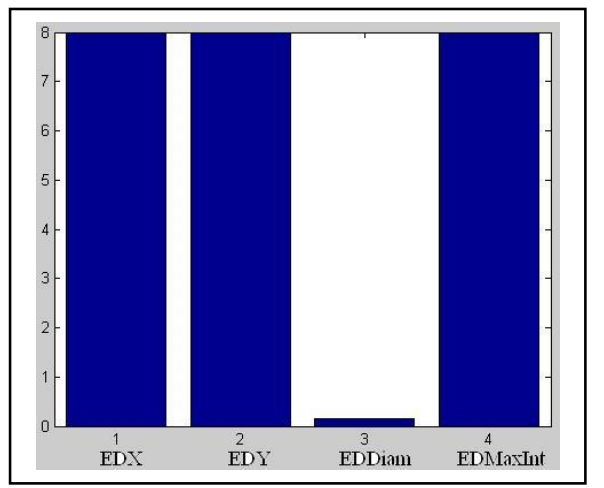

(c)

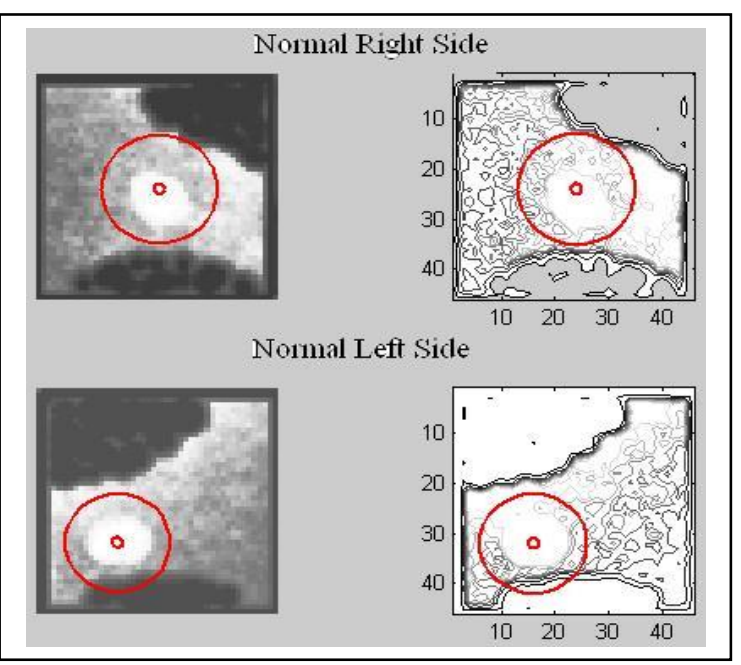

(b)

Figure (10): (a) Normal case. (b) Result of Program. (c) Euclidean Result.

\section{Conclusions}

1. We used Mask Technique to capture the desired area. This technique gives high accuracy and reduces the execution time required to detect the head of femur, and can be used to detect other problems.

2. Finds new features Diameter and center detection which can be used for any problem which has a shape like circle.

3. Do not need this system for large memory, but a small memory to store the picture before diagnosis and another to store the captured section to calculate the center $(2 \times 2)$ only. 
4. This diagnosis system is very simple and do not need any steps or rotations to learn like artificial techniques, and this helps to reduce the execution time required to detect the head of femur.

5. This diagnosis system helps to diagnose one of the $\mathrm{CDH}$ effects on the upper end of the femur bone for child which the doctor to observe one of the affections of $\mathrm{CDH}$, but not to diagnoses the degree of $\mathrm{CDH}$.

6. In the future this system needs a library with normal measurements to compare with, like the normal size of head of femur for each child age. 


\section{REFERENCES}

[1] Barnett, C.H. ; DV Davies, ; M.A. Macconail (1980) "The hip joint In: William and Warnick (eds). Gray's anatomy", $36^{\text {th }}$ ed. Chirchill Livingstone, London. UK., PP.477-482.

[2] Beaty, J.H. (1998) Congenital and developmental anomalies of the hip and pelvis. In: Canale ST, Cambell's Operative Surgery. $9^{\text {th }}$ ed. Mosby. St Louis, USA, PP.1021-1022.

[3] Scott, E. Umbaugh (1998) "Computer Vision and Image Processing", Prentice-Hall, Inc.

[4] The Math Works, Inc. (2004) "MATLAB®: The Language of Technical Computing", Version 7.0.0.19920 (R14).

[5] Tinku Acharya and Ajoy K. Ray (2005) "Image Processing Principles and Applications", Hoboken, New Jersey Published simultaneously in Canada, Published by John Wiley \& Sons, Inc.

[6] Zhu Yong ; Tan Tieniu and Wang Yunhong (2000) "Biometric Personal Identification Based on Iris Patterns", 15th International Conference on Pattern Recognition (ICPR). 